\title{
Integrating different understandings of landscape stewardship into the design of agri-environmental schemes ${ }^{1}$
}

\author{
CHRISTOPHER M. RAYMOND ${ }^{1,2}$, MARK REED ${ }^{3}$, CLAUDIA BIELING ${ }^{4}$, GUY M. \\ ROBINSON $^{5}$ AND TOBIAS PLIENINGER $^{6}$
}

1 Swedish University of Agricultural Sciences (SLU) - Department of Landscape Architecture, Planning and Management, Alnarp, Sweden

2 Enviroconnect, Stirling, South Australia, Australia

3 Newcastle University - HEFCE N8 Agri-Food Resilience Programme, Institute for Agri-Food Research \& Innovation and Centre for Rural Economy, Newcastle upon Tyne, UK

4 University of Hohenheim - Institute of Social Sciences in Agriculture, Stuttgart, Germany

5 University of Adelaide - Department of Geography, Environment and Population, Adelaide, Australia

6 University of Copenhagen - Department of Geosciences and Natural Resource Management, Frederiksberg, Denmark

\section{Corresponding author:}

Christopher M. Raymond, e-mail: chris.raymond@enviroconnect.com.au

\footnotetext{
1 This text is a preprint. Please cite as: Raymond C.M., M. Reed, C. Bieling, G.M. Robinson, T. Plieninger (2016): Integrating different understandings of landscape stewardship into the design of agri-environmental schemes. Environmental Conservation 43: 350-358. The original publication is available at: http://dx.doi.org/10.1017/S037689291600031X.
} 


\begin{abstract}
While multiple studies have identified land managers' preferences for agri-environmental schemes (AES), few approaches exist for integrating different understandings of landscape stewardship into the design of these measures. We compared and contrasted rural land managers' attitudes toward AES and their preferences for AES design beyond 2020 across different understandings of landscape stewardship. Forty semi-structured interviews were conducted with similar proportions of small holders, medium holders and large holders in southwest Devon, UK. Overall, respondents most frequently cited concerns related to the reduced amount of funding available for entry-level and higher-level stewardship schemes in the UK since 2008, changing funding priorities, perceived overstrict compliance and lack of support for farm succession and new entrants into farming. However, there were differences in concerns across understandings of landscape stewardship, with production respondents citing that AES do not encourage food production, whereas environmental and holistic farmers citing that AES do not support the development of a local green food culture and associated social infrastructure. These differences also emerged in preferences for AES design beyond 2020. We adapted a collaborative and coordinated approach for designing AES to account for the differing interests of land managers based on their understanding of landscape stewardship. We discuss the implications of this approach for environmental policy design in the European Union and elsewhere
\end{abstract}

\title{
Keywords
}

agri-environmental measures, collaborative management, common agricultural policy, community-based natural resource management, landscape stewardship, payments for ecosystem services 


\section{Introduction}

Agri-environmental schemes (AES) are mechanisms by which landowners and other individuals and bodies responsible for land management (collectively referred to as 'land managers' herein) can be incentivized to manage their environment. Between 2007-2013, the European Union (EU) spent $€ 23$ billion on AES, covering 46.9 million hectares (European Commission 2015). The latest re-negotiation of the EU's Common Agricultural Policy (CAP) for 2014-2020 enables spending on AES to rise to €25 billion (European Commission 2015).

While the overall amount of funding earmarked for environmental schemes has increased from $25 \%$ in the previous CAP period to $30 \%$ now, the budget needs to cover a wider range of objectives including climate change mitigation, organic farming and so called 'climate and environment investment measures' (Pèer et al. 2014). Such widening has increased the complexity of scheme design and evaluation. In response, researchers have developed governance models to support the design and evaluation of the next wave of AES (Prager et al. 2012, 2015; Reed et al. 2014; Prager 2015), which draw upon governance principles for encouraging collaboration across institutional levels (Newig \& Fritsch 2009; Robinson \& Berkes 2011; Newig \& Koontz 2013).

A range of participatory techniques have also been developed to support the integration of multiple objectives into landscape planning. These techniques include: collective visioning to support future changes to land use (Meyer et al. 2015); the mapping of local stakeholder values to inform priorities for conservation (Raymond et al. 2009; Whitehead et al. 2014); and segmenting land managers according to different types of values and farming motivations (Emtage et al. 2001; Köbrich et al. 2003; Maybery et al. 2005; Bidogeza et al. 2009; Morrison et al. 2011).

Here we are particularly interested in how framing can be used as a tool for designing AES with multiple objectives. Much research attention has been devoted to framing in communication which examines how the use of different words or phrases affects local attitudes (Druckman 2001). Studies have focused on assessing participants' responses to a variety of gain or loss frames, including frames related to the adoption of soil conservation practices (Andrews et al. 2013) or attitudes toward climate change (Spence \& Pidgeon 2010; Gifford \& Comeau 2011; Jones \& Song 2014). What is missing in these current debates is how landholders' understanding of land management, in this case landscape stewardship, may influence their concerns and preferences for AES design. This is essentially an issue of 'frames in thought'. Unlike frames in communication, frames in thought refers to an individual's perception and understanding of a situation and what he/she believes to be the most salient aspect of an issue (Druckman 2001).

Research into frames in thought is relatively new in the conservation sciences. A plurality of understandings of people and nature has previously been found, which therefore encourages conservation planners to consider a range of approaches to conservation (Linnel et al. 2015). In southwest (SW) Devon (UK), land managers held various understandings of landscape stewardship (herewith distinguished in four categories: environmental, production, holistic and instrumental) underpinned by different land management motivations (Raymond et al. 2016). We suggest that frames in thought is an important area to study considering that 'stewardship' is a nebulous term and is likely to be subject to multiple interpretations among land managers (Robinson 2008). Further, we suggest that understanding of stewardship may have a bearing on attitudes toward existing AES and preferences for future design. 
In this study, we compared and contrasted land manager concerns regarding existing AES and their preferences for future scheme design (beyond 2020) across different understandings of landscape stewardship. Results are drawn from a thematic analysis of 40 semi-structured interviews with land managers in SW Devon. We focus on SW Devon because of the diversity of land use types and land managers in the region, ranging from small holders involved in community-supported agriculture initiatives through to large-scale, commercial dairy operations. We use the results to propose a collaborative approach to AES design, which may assist national and regional policy makers to effectively engage land managers and catchment bodies in CAP reforms beyond 2020. After presenting a collaborative approach to AES design, we identify some of the challenges and opportunities associated with integrating land manager preferences into environmental policy and planning.

\section{Methods}

The study is a combination of a qualitative survey in the form of semi-structured interviews with land managers and the development of an approach for designing AES involving land managers and other stakeholders.

\section{Study area}

The study area is situated in SW Devon, a county in the SW of England. The physical geographic boundaries are the Dart River on the eastern boundary, the watershed of the Dartmoor upland to the north, the Tamar Valley to the west and the English Channel to the south. Dominant agricultural land uses include cereals and other cropping, horticulture, pigs and poultry. The upland area of Dartmoor is a National Park and as such is subject to administration by the Dartmoor National Park Authority. The southern part of the study area, up to and including the coastline, is contained within a designated Area of Outstanding Natural Beauty (Bieling \& Bürgi 2014).

\section{Sample}

A snowball sampling strategy was used to identify participants for the study. Suggested participants were stratified into small holders of $<2$ ha, medium holders of 2-40.5 ha and large holders of $>40.5$ ha. We sought representation across land management types of conventional and organic, and land uses of dairy, sheep and cattle, vegetables, communitysupported agriculture and cereal cropping. The final number of interviews by land manager type was guided by principles of data saturation, a key component of both grounded theory analysis (Strauss \& Corbin 1990) and thematic analysis (Braun \& Clarke 2013). For further information on the sampling technique see Raymond et al. (2016).

\section{Interview technique}

Forty (average 45 minute) semi-structured interviews were conducted at land managers' residences in SW Devon between October and December 2014. Each interview followed an interview script which was developed and tested in partnership with local stakeholders comprising members of South Hams Council and a local landscape consultancy (see Raymond et al. (2016) for further details). 


\section{Stewardship classification}

Given the absence of a coherent set of definitions for understanding stewardship, four understandings of stewardship using grounded theory analysis have been identified: 'environmental', 'production', 'holistic' and 'instrumental' (Raymond et al. 2016). An open coding approach was used first to find the core understandings of stewardship. Selective coding techniques were then used to relate data coded at an earlier date to the core understandings of stewardship.

Environmental respondents defined stewardship as looking after the land in an environmental way, managing the environmental features, protecting these features for future generations, taking care of the environment and implementing measures that encourage wildlife. For example, one respondent stated: 'Well stewardship means looking after your land in an environmental way, keeping it preserved for the next generation and look out for the wildlife and what you can do to save wildlife.'

Respondents from the production category defined stewardship as keeping land productive or in terms of the preservation of traditional farming techniques. They under-rated or did not mention the wildlife conservation goals cited by environmental respondents. Key discourses communicated as part of this framing include: 'to keep the land in good productive condition for future generations' and 'to preserve traditional farming techniques'. Farmers discussed stewardship in the context of 'land management' and 'maintaining its productivity'.

Holistic respondents recognized the interactions, and sometimes the interdependencies, between ecological and production systems. They also highlighted the important role of maintaining or enhancing landscape diversity by supporting a patchwork of different land uses. For example, one respondent stated: 'To me, landscape stewardship is to keep what we've got, i.e., the patchwork fields, the hedgerows, the natural hedgerows that people think are natural but they're not, they're man-made.'

Instrumental respondents defined stewardship in the context of a government policy or incentive scheme, despite prompting for a wider definition of stewardship. Stewardship was considered as a formal government scheme to support environmental actions. Emphasis was placed on environmental agreements and land managers being paid to do something to support the natural environment. For example, one respondent noted: 'I would say at the moment in England it would be our environmental agreements which would be Higher Level Stewardship, Uplands Entry Level Stewardship and Entry Level Stewardship.'

\section{Analysis}

Inductive thematic analysis techniques were applied to identify themes and sub-themes of concerns about AES among land managers in SW Devon. In an inductive approach, the process of coding occurs without trying to fit the data into a pre-existing model. This pinpoints, examines and records patterns or 'themes' within data. Thematic analysis was performed through a process of: (1) reading and familiarization with the interview transcripts and (2) complete coding to identify issues relevant to land manager concerns about AES and preferences for scheme design beyond 2020, which reflects the starting time for the next iteration of AES in the EU. For each individual code we then collated all instances of text where that code appeared in the dataset. Themes were developed when codes clustered 
together. Each theme was linked to the underpinning code and then reviewed and revised, checking to ensure the themes fitted well with the data. The themes were then revised by coding and collating more data from the original interview transcripts. Presence or absence was then recorded for each theme, together with the percentage of all respondents who mentioned that theme. Each theme was then analysed for its presence or absence by understanding of stewardship. We assigned themes to inform the collaborative approach for designing AES. We also recorded the number and percentage of respondents who referred to each theme.

\section{Results}

Similar proportions of respondents with environmental, production, holistic and instrumental understandings of stewardship were interviewed. Overall, ten interviewees aligned with the environmental understanding, six with production, 13 with holistic and 11 with instrumental. Environmental respondents were younger and more formally educated, but less financially secure than respondents espousing a production oriented or instrumental understanding. They also owned or managed less land than production and holistic respondents.

There were different levels of participation in stewardship schemes across study respondents. None of the small holders interviewed received the basic farm payment or entry-level subsidy given that they were under the 5 ha threshold prescribed in national AES regulations. All medium holders received both the basic farm payment and entry-level stewardship subsidies. A total of $80 \%$ of large holders interviewed received both the basic farm payment and entrylevel stewardship.

\section{Respondents' concerns about existing AES}

Respondents identified a range of concerns about the design of AES. They most frequently cited the reduced amount of funding available for entry-level and higher-level stewardship schemes in the UK since 2008 (38\% of all respondents), changing (and short-term) funding priorities and rules (33\%), perceived overstrict compliance (25\%) and lack of support for farm succession and new entrants into farming (25\%) (Table 1). Changing (and short-term) funding priorities were of particular concern to environmental respondents who found it difficult to manage biodiversity as a result of changing funding priorities. One respondent noted: 'They want us to clear it out to allow biodiversity in with the natural grasses and flowers and all the rest of it, and they pay for the first three years to go in there with one of these heavy duty swipes, and swipe, but after that there's nothing.'

Environmental, production and instrumental respondents frequently commented that scheme applications and management requirements were too complex and restrictive, particularly higher-level stewardship and animal welfare regulations. Land managers were often reluctant to implement innovative management techniques as a result of fear of retribution. They believed that many of the prescribed measures were irrelevant to their farm, and in some cases, negatively affected both biodiversity and cultural diversity. One respondent noted: 'They actually bring a tape measure out. If you see two [xxxx] men, two people in a field with heads down and backsides up, they're from the [one of the national environmental agencies]. They're not there to help us ... never felt that. It's the same with all the animal movements 
and everything else ... It's the bureaucratic nightmare above us that causes us the biggest headache.'

Many respondents accepted that reduced funding of AES was a reality; however, they were concerned about the lack of funding certainty. In some instances, land managers were not informed about changes to schemes until six months before the changes came into effect, which was too short given that they work on two- to three-year farm planning cycles.

The undervaluing of local knowledge by government organizations was frequently mentioned, particularly in the context of managing stocking rates on Dartmoor. One respondent noted: 'They don't give enough weight to my knowledge of what is best for this farm. I'm the fourth generation here. We have a very good understanding of what we can and can't do.' In some instances, the undervaluing of local knowledge was communicated as government ignorance, one respondent stating: 'One of the biggest problems that we experience is people's ignorance as to what farming is about. Government ignorance! ... There are a lot of rules and regulations that seem to be set arbitrarily on a date - whereas Mother Nature is saying, well actually on that date you don't want to be turning your animals up onto the moor to maintain the stocking rate.'

The difficulties associated with young people entering farming are as much a scheme issue as a structural issue. With the exception of environmental respondents, all interviewees were of the view that AES encouraged large landholders to take on more land to increase their disposable income even though they may have no intention of farming it. This in-turn created the perception that schemes did not support food production. As one respondent commented: 'Because I don't think it [basic farm payment or entry-level stewardship] encourages people to produce food. So if someone mows the land once a year they still get paid. You don't have to keep sheep on it. You don't have to grow any vegetables, so I think farming for me should be about production of food '.

Land managers in the study area assigned cultural values to their property and to the SW Devon region; however, all interviewees with the exception of instrumental respondents were concerned that there was an implied expectation from government and local pressure groups to manage those values (otherwise termed by respondents as a 'theme park') without any additional funding. Others raised concerns that AES do not support the interests of small holders aspiring to develop a local, 'green food' culture; nor the local infrastructure, such as abattoirs and meat processing units, required to build that industry. Some of these concerns may have been fuelled by recent increases to the acreage (to 10 ha) required for AES eligibility.

Among holistic respondents, there was a general perception that AES were not keeping pace with changes to UK consumer culture, particularly the increasing demand for traceable local food of known provenance and production method. These concerns were aggregated under the 'do not support small holder interests' theme (Table 1). Interestingly, production and instrumental respondents did not refer to any of these wider cultural values, potentially because they did not have any linkages to community-supported agriculture initiatives.

In summary, many respondents' concerns related to the perceived fairness of AES as applied in SW Devon and the capability of the schemes to provide ongoing and certain funding. There is an obvious tension between retaining the range of environmental and production benefits supported by existing AES versus providing for a broader range of values and interests 
frequently supported by holistic land managers. In the next section, we explore suggested improvements to AES beyond 2020.

\section{Suggested improvements to the design of AES beyond 2020}

Respondents suggested a range of improvements to the design of AES beyond 2020 (Table 2). Production respondents often encouraged the tailoring of agri-environmental investments to finer scales of management, in some cases to particular types of farm systems (35\%) and in other cases to catchments (20\%). For example, one production respondent noted: 'It's [land management targets are] taken on an England-wide basis. They say it might be tweaked for an area but what they might call heather moorland is not like in the Pennines, so perhaps there isn't enough individuality and not enough localism within their targets.' Another production respondent commented: 'there are no two farms in the whole of this country the same, they have all got their vagaries and their differences.... And there's not enough understanding of the differences.'

Some holistic respondents suggested that tailoring schemes in this way would provide for both biodiversity and cultural diversity. For example: 'Personally what I like to try and create on my farm is a random habitat because within a random habitat one year something has a good year then another year something else has a [good year].'

Environmental respondents often suggested designing schemes in ways which promote linkages between habitats and creating programs targeted at catchments rather than individual farms. One such respondent noted: 'I think maybe looking at linking habitats rather than a particular farm in isolation. For example, we've got invasive weeds on the river and for me it's a concern and they weren't there five to ten years ago and . . . I tried my hardest to pull it up but all the while there is a seed source upstream.'

Respondents urged better communication of agri- environmental scheme funding rules (25\%) and a lighter touch to compliance (15\%) to increase land manager confidence in managing their land for biodiversity and cultural diversity. Many respondents chose not to experiment with more innovative biodiversity or cultural diversity management options because they had not been adequately informed about them or feared retribution from authorities.

To increase land manager capability to manage their land for a range of values, a few respondents noted the potential for more education and training about innovative management techniques (18\%), greater incentives to encourage young people into farming (8\%) and greater funding support for the management of heritage buildings, archaeological sites and tourism/recreation areas (8\%), which are on commons or private land in some cases (Table 2). Holistic respondents more frequently cited a need to consider a wider range of values in future AES than environmental and production respondents.

Small holders, particularly holistic respondents, suggested a range of initiatives that could be implemented to support their interests, most of which involved the support of a 'local, green food culture'. This included support for training schemes which educated citizens about the importance of locally grown and organic foods; support for traditional farming practices, such as traditional hedge laying, the use of manual labour in different stages of crop production and regular crop rotations to maintain nutrients in the soil; and support for the development of local infrastructure so that land managers could value-add to produce. 
Some large holders suggested that AES should be abandoned altogether because they were perceived to inflate food prices and create an uncompetitive agricultural industry in the UK. This view was neither shared by environmental respondents, nor many holistic respondents. On the contrary, many environmental and holistic respondents urged an expansion of supported values and for government authorities to communicate funding rules and supported practices more effectively, such as improving the timeliness of and access to information.

\section{Discussion}

We compared and contrasted land manager concerns regarding existing AES and their preferences for future scheme design (beyond 2020) across different understandings of landscape stewardship. We revealed different preferences for the design of AES beyond 2020, many of which are linked to different understandings of landscape stewardship. Most respondents supported the continuation of AES, but with improvements to the scale at which they are applied and communicated, the types of objectives supported, and simplifications to the application and administration process. There are obvious tensions between managing for values at the catchment scale versus managing values according to site-based characteristics. Therefore, a key challenge is how to develop a new set of schemes which support different understandings of stewardship, are relatively simple to apply and understand, and in the process, support multiple elements of good governance and the principles of biodiversity and cultural diversity.

These results point towards the need for a more deliberative and community-led approach to future design, including new ways to: better value local knowledge; support farm succession; communicate funding rules; and educate and train land managers in natural resource management. One of the challenges of such a deliberative approach is to ensure a fair and transparent process for identifying and agreeing on management objectives. Following Prager (2015), we suggest that a balanced approach of collaboration (land managers meeting together and maintaining a dialogue) and coordination (land managers working on the same objective but in isolation) is required to address competing needs. We also see the potential of a continuum of approaches from coordination to collaborative and government-led to community-led depending on whether the management issue is of shared private or public interest. By shared private interest we refer to issues that are collectively viewed as important by land managers with common understandings of landscape stewardship. Shared public interest refers to those issues which the wider community (including catchment-level organizations) view as important to manage, but may not be deemed important at the individual farm level by land manager consortia.

Dealing with conflicting notions of landscape stewardship is one of the major challenges associated with implementing a collaborative and coordinated approach of AES. How can policy makers support collaboration if they do not know what understandings of stewardship exist and how they relate to policy concerns and preferences? The framing in thought approach presented here is a useful means of firstly identifying shared understandings of landscape stewardship (as per Raymond et al. 2016) and then linking these notions to AES concerns and preferences. Based on the presence/absence analysis, it is clear that respondents with an environmental or holistic understanding of landscape stewardship were more likely to note that the existing schemes do not support small holder interests for a local/green food culture, nor support local infrastructure. It would therefore be prudent for policy makers to 
consider how AES could be tailored to the local, 'green food' culture interests of small holders, and simultaneously provide support for local infrastructure such as schools and markets to support this objective.

More broadly, we see a role for our approach in providing a starting point for negotiations between conservation and production groups which were previously identified as having conflicting objectives. Our findings reveal that land managers with a production view have shared preferences with land managers with an environmental, holistic and instrumental view of stewardship. All respondent groups reported concerns about reduced funding, overstrict compliance, lack of support for farm succession and changing funding priorities. They also had shared preferences for tailoring investments to farm systems, more education and training courses and higher subsidies to support a range of cultural values. Based on these findings, there are clearly areas of common ground which could be used as a foundation for future discussions about AES redesign. We suggest that this collaboration should occur at a local level. Farmer-led consortia, each reflecting a shared understanding of landscape stewardship, agree on the type of stewardship outcomes they plan to deliver. These plans should communicate a distinguishing set of land management priorities. An independent facilitator and intermediary body could support a consensus view, which is then translated into a local collaborative management plan.

\section{Challenges associated with a coordinated and collaborative approach to agri- environmental scheme design}

We recognize that there are a range of monetary, political and regulatory challenges associated with catering for the needs of specific groups according to our proposed approach. The first major challenge is the long productivist tradition in the CAP (Lowe et al. 2010), which has led to a movement away from the preservation of 'public goods' to a focus on multi-functionality. The multi-functionality discourse is there to achieve various things, such as providing consumers and the processing industry with 'healthy and quality food' and ensuring 'the sustainable use' of natural resources, protecting 'biodiversity', generating 'employment' and contributing to the 'well-tended countryside' (Erjavec \& Erjavec 2015). Placing all control in land managers' hands could lead to a situation where biodiversity values could be lost in the face of competing multi-functional objectives. Hence, there is an important role for national agencies and conservation NGOs to work in collaboration with private land managers to ensure a range of objectives is met. For this reason, we suggest that some issues which span property boundaries, such as habitats of public interest and diffuse pollution, need to be supported through coordinated, government-led approaches, particularly when they are not perceived to be of shared private interest. Catchment management agencies and NGOs have an important role in working with national environmental agencies and private landholders to ensure these objectives are met. We recognize the potential for tradeoffs to occur in this process of negotiation given that objectives identified by land manager consortia may conflict with those identified by catchment organizations. We therefore encourage future research on trade-offs to better understand how, where and when they can be managed.

A second major challenge concerns whether landholders would be willing to collaborate in AES objective setting and delivery. There is evidence that land managers support such collaboration. For example, the Dartmoor Farming Futures Initiative (UK) offers land 
managers more responsibility for the design of AES. In the first stage of the pilot, land managers identified a range of ecosystem services that could be delivered from the land from food production to water management where applicable. The initiative then facilitated a collaborative approach to agreeing on the outcomes sought, delivering the management required and assisting with the monitoring of the process (Dartmoor Farming Futures 2013). An independent review revealed that this initiative facilitated greater understanding of what AES are trying to achieve. Land managers reported great awareness of habitats, species and other environment features on their common and greater responsibility for the design of AES (Silcock et al. 2013). In another example, the Dutch Government is encouraging land managers to develop their own environmental plans which need to conform to local and regional landscape-scale objectives. A range of agri-environmental cooperative groups has been established representing land managers, citizens, municipalities and nature conservation interests. Each group develops a collective management plan to address goals, features of the working area, activities and measures, organization and cooperation (including monitoring) as well as planning and financing (de Lijster \& Prager 2012).

Key to success of these programs is trust through fair processes. Empirical work demonstrates that such trust makes conflict resolution more likely and thus building and maintaining trust with land managers is central to conserving biodiversity (Young et al. 2016). However, such trust building requires effort and resources, including a commitment to open and transparent facilitation. The importance of local level facilitators of landscape stewardship is now being recognized by the UK Government. For example, the Rural Development Program for England has a Countryside Stewardship Facilitation Fund to 'bring farmers, foresters and other land managers together to improve the local natural environment at a landscape scale ... [via] partnership and a collective approach across holdings to deliver shared environmental outcomes that go beyond what could be delivered by individual holdings acting in isolation' (DEFRA 2015). Our approach takes this a step further, by proposing a role for intermediary bodies that can link land managers to catchment-level organizations via the facilitators with whom they work. By catchment-level organizations we refer to local municipalities, nature conservation groups, environmental organizations and individuals with a conservation interest. These links may be direct, via joint workshops with the wider stakeholder community, or indirect, with the facilitator representing these wider interests to the group.

\section{Conclusions}

We compared and contrasted rural land manager concerns regarding AES and preferences for design across different understandings of landscape stewardship. Overall, respondents most frequently cited concerns related to the reduced amount of funding available for entry-level and higher-level stewardship schemes in the UK since 2008, changing (and short-term) funding priorities, perceived overstrict compliance and lack of support for farm succession and new entrants into farming. However, there were differences across understandings of landscape stewardship with production respondents citing that AES do not encourage food production and with environmental and holistic land managers citing that AES do not support the development of a local green food culture and associated social infrastructure. We then proposed an approach to designing AES in collaboration and coordination with rural land managers, taking into account their different understandings of stewardship and preferences for AES beyond 2020. The collaborative approach holds promise for identifying areas of 
common ground between groups previously perceived to be in conflict with one another. However, there are a range of challenges to implementation, including the multi- functional discourse in CAP reforms, the time, cost and effort required to build trust among partners and the political challenges associated with redirecting funding into organic food production at a local scale.

\section{Acknowledgements}

This research received support through Grant 603447 (Project HERCULES) from the European Commission (7th Framework Program). The paper is a contribution to the Programme on Ecosystem Change and Society (www.pecs-science.org) and the Global Land Project (www.globallandproject.org). We would like to thank the 60 attendees of a HERCULES workshop on 'Landscape Stewardship: Integrating a broad suite of landscape values into rural development policies’ (03.06.15, European Economic and Social Committee, Brussels) for constructive discussions. 


\section{References}

Andrews, A.C., Clawson, R.A., Gramig, B.M. \& Raymond, L. (2013) Why do farmers adopt conservation tillage? An experimental investigation of framing effects. Journal of Soil and Water Conservation 68: 501-511.

Bidogeza, J.C., Berentsen, P.B.M., De Graaff, J. \& Oude Lansink, A.G.J. M. (2009) A typology of farm households for the Umutara Province in Rwanda. Food Security 1: 321-335.

Bieling, C. \& Bürgi, M. (2014) List and documentation of case study landscapes selected for HERCULES. EU-Project Deliverable GA no. 603447 [www document]. URL www.herculeslandscapes.eu/tartalom/HERCULES_WP3_D3_1_ALUFR_final.pdf

Braun, V. \& Clarke, V. (2013) Successful Qualitative Research: a Practical Guide for Beginners. 1st Edition, ed. M. Carmichael. London, UK: Sage Publications.

Dartmoor Farming Futures (2013) Dartmoor Farming Futures - Developing a New Approach to $\begin{array}{llll}\text { Agri-Environmental Delivery [www document]. URL } & \end{array}$ www.dartmoor.gov.uk/lookingafter/laflandmanagement/dartmoor-farming-futures

De Lijster, E. \& Prager, K. (2012) The use of indicators in agri-environmental management in the Netherlands. Commissioned Report, James Hutton Institute, UK [www document) URL www.macaulay.ac.uk/LandscapePartners/ ReportAnalysisLandscapePartners_July.pdf

DEFRA (2015) Guide to Countryside Stewardship: facilitation fund [www document]. URL www.gov.uk/government/ publications/guide-to-countryside-stewardship-facilitationfund/guide-to-countryside-stewardship-facilitation-fund

Druckman, J.N. (2001) The implications of framing effects for citizen competence. Political Behavior 23: 225-256.

Emtage, N.F., Harrison, S.R. \& Herbohn, J.L. (2001) Landholder attitudes to and participation in farm forestry activities in sub- tropical and tropical eastern Australia. In: Sustainable Farm Forestry in the Tropics, eds. S.R. Harrison \& J.L. Herbohn. Cheltenham, UK: Edward Elgar.

Erjavec, K. \& Erjavec, E. (2015) 'Greening the CAP' - just a fashionable justification? A discourse analysis of the 2014-2020 CAP reform documents. Food Policy 51: 53-62.

European Commission (2015) EU Agriculture Spending: Focused on Results. European Commission Fact Sheet [www doc- ument]. http://ec.europa.eu/agriculture/cap-funding/pdf/cap- spending09-2015_en.pdf

Gifford, R. \& Comeau, L.A. (2011) Message framing influences perceived climate change competence, engagement, and behavioral intentions. Global Environmental Change - Human and Policy Dimensions 21: 1301-1307.

Jones, M.D. \& Song, G. (2014) Making sense of climate change: how story frames shape cognition. Political Psychology 35: 447-476.

Köbrich, C., Rehman, T. \& Khan, M. (2003) Typification of farming systems for constructing representative farm models: two illustrations of the application of multi-variate analyses in Chile and Pakistan. Agricultural Systems 76: 141-157.

Linnell, J.D.C., Kaczensky, P., Wotschikowsky, U., Lescureux, N. \& Boitani, L. (2015) Framing the relationship between people and nature in the context of European conservation. Conservation Biology 29: 978-85. 
Lowe, P., Feindt, P.H. \& Vihinen, H. (2010) Introduction: greening the countryside? Changing frameworks of EU agricultural policy. Public Administration 88: 287-295.

Maybery, D., Crase, L. \& Gullifer, C. (2005) Categorising farming values as economic, conservation and lifestyle. Journal of Economic Psychology 26: 59-72.

Meyer, W.S., Bryan, B.A., Summers, D.M., Lyle, G., Wells, S., McLean, J. \& Siebentritt, M. (2015) Regional engagement and spatial modelling for natural resource management planning. Sustainability Science. DOI: 10.1007/s11625-015-0341-5.

Morrison, M., Durante, J., Greig, J., Ward, J. \& Oczkowski, E. (2011) Segmenting landholders for improving the targeting of natural resource management expenditures. Journal of Environmental Planning and Management 55: 17-37.

Newig, J. \& Fritsch, O. (2009) Environmental governance: participatory, multi-level - and effective? Environmental Policy and Governance 19: 197-214.

Newig, J. \& Koontz, T.M. (2013) Multi-level governance, policy implementation and participation: the EU's mandated participatory planning approach to implementing environmental policy. Journal of European Public Policy 21: 248-267.

Pèer, G., Dicks, L.V., Visconti, P., Arlettaz, R., Báldi, A., Benton, T.G., Collins, S., Dieterich, M., Gregory, R.D., Hartig, F., Henle, K., Hobson, P.R., Kleijn, D., Neumann, R.K., Robijns, T., Schmidt, J., Shwartz, A., Sutherland, W.J., Turbé, A., Wulf, F. \& Scott, A.V. (2014) Agriculture policy. EU agricultural reform fails on biodiversity. Science 344: 1090-1092.

Prager, K. (2015) Agri-environmental collaboratives for landscape management in Europe. Current Opinion in Environmental Sustainability 12: 59-66.

Prager, K., Nienaber, B., Neumann, B. \& Phillips, A. (2015) How should rural policy be evaluated if it aims to foster community involvement in environmental management? Journal of Rural Studies 37: 120-131.

Prager, K., Reed, M. \& Scott, A. (2012) Encouraging collaboration for the provision of ecosystem services at a landscape scale - rethinking agri-environmental payments. Land Use Policy 29: 244- 249.

Raymond, C.M., Bieling, C., Fagerholm, N., Martin-Lopez, B. \& Plieninger, T. (2016) The farmer as a landscape steward: comparing local understandings of landscape stewardship, landscape values, and land management actions. Ambio 45: 173- 184.

Raymond, C.M., Bryan, B.A., MacDonald, D.H., Cast, A., Strathearn, S., Grandgirard, A. \& Kalivas, T. (2009) Mapping community values for natural capital and ecosystem services. Ecological Economics 68: 1301-1315.

Reed, M.S., Moxey, A., Prager, K., Hanley, N., Skates, J., Bonn, A., Evans, C.D., Glenk, K. \& Thomson, K. (2014) Improving the link between payments and the provision of ecosystem services in agri-environment schemes. Ecosystem Services 9: 44-53.

Robinson, G.M. (2008) Sustainable rural systems: an introduction. In: Sustainable Rural Systems: Sustainable Agriculture and Rural Communities, ed. G.M. Robinson, pp. 3-40. Basingstoke, UK and Burlington, VT, USA: Ashgate.

Robinson, L.W. \& Berkes, F. (2011) Multi-level participation for building adaptive capacity: formal agency-community interactions in northern Kenya. Global Environmental Change 21: 11851194. 
Silcock, P., Brunyee, J. \& Pring, J. (2013) Dartmoor Farming Futures Project: An Independent Evaluation. Commissioned Report. Worcestershire, UK: Cumulus Consultants Ltd.

Spence, A. \& Pidgeon, N. (2010) Framing and communicating climate change: the effects of distance and outcome frame manipulations. Global Environmental Change - Human and Policy Dimensions 20: 656-667.

Strauss, A.L. \& Corbin, J. (1990) Basics of Qualitative Research Techniques and Procedures for Developing Grounded Theory. Thousand Oaks, USA: Sage.

Whitehead, A.L., Kujala, H., Ives, C.D., Gordon, A., Lentini, P.E., Wintle, B.A., Nicholson, E. \& Raymond, C.M. (2014) Integrating biological and social values when prioritizing places for biodiversity conservation. Conservation Biology 28: 992- 1003.

Young, J.C., Searle, K., Butler, A., Simmons, P., Watt, A.D. \& Jordan, A. (2016) The role of trust in the resolution of conservation conflicts. Biological Conservation 195: 196-202. 
Table 1: Respondent concerns about existing stewardship schemes. $\sqrt{ }=$ theme present within that framing of landscape stewardship; $\mathrm{X}=$ theme absent in that framing of landscape stewardship.

\begin{tabular}{|c|c|c|c|c|c|c|}
\hline Concerns & $\begin{array}{l}\text { Respondents } \\
\text { citing theme }\end{array}$ & $\begin{array}{l}\% \text { of } \\
\text { sample }\end{array}$ & $\begin{array}{l}\text { Environmental } \\
(\mathrm{n}=10)\end{array}$ & $\begin{array}{l}\text { Production } \\
(\mathrm{n}=6)\end{array}$ & $\begin{array}{l}\text { Holistic } \\
(\mathrm{n}=13)\end{array}$ & $\begin{array}{l}\text { Instrumental } \\
(\mathrm{n}=11)\end{array}$ \\
\hline Reduced funding & 15 & 38 & $\sqrt{ }$ & $\sqrt{ }$ & $\sqrt{ }$ & $\sqrt{ }$ \\
\hline $\begin{array}{l}\text { Overstrict } \\
\text { compliance }\end{array}$ & 13 & 33 & $\sqrt{ }$ & $\sqrt{ }$ & $\sqrt{ }$ & $\sqrt{ }$ \\
\hline $\begin{array}{lr}\text { Government } & \\
\text { undervaluing local } \\
\text { land manager } \\
\text { knowledge } \\
\text { interests }\end{array}$ & 10 & 25 & $\sqrt{ }$ & $\mathrm{X}$ & $\sqrt{ }$ & $\sqrt{ }$ \\
\hline $\begin{array}{l}\text { Lack of support for } \\
\text { farm successionand } \\
\text { new entrants }\end{array}$ & 10 & 25 & $\sqrt{ }$ & $\sqrt{ }$ & $\sqrt{ }$ & $\sqrt{ }$ \\
\hline $\begin{array}{l}\text { Changing funding } \\
\text { priorities andrules } \\
\text { (policy uncertainty) }\end{array}$ & 9 & 23 & $\sqrt{ }$ & $\sqrt{ }$ & $\sqrt{ }$ & $\sqrt{ }$ \\
\hline $\begin{array}{l}\text { Too prescriptive } \\
\text { and complex }\end{array}$ & 7 & 18 & $\sqrt{ }$ & $\sqrt{ }$ & $\mathrm{X}$ & $\sqrt{ }$ \\
\hline $\begin{array}{lr}\text { Do not } & \text { support } \\
\text { small } & \text { holder } \\
\text { interests } & \end{array}$ & 5 & 13 & $\sqrt{ }$ & $\mathrm{X}$ & $\sqrt{ }$ & \\
\hline $\begin{array}{l}\text { Do not support local } \\
\text { infrastructure }\end{array}$ & 4 & 10 & $\mathrm{~F}$ & $\mathrm{X}$ & $\sqrt{ }$ & $\sqrt{ }$ \\
\hline $\begin{array}{l}\text { Do not encourage } \\
\text { food production }\end{array}$ & 3 & 8 & $\mathrm{X}$ & & & \\
\hline $\begin{array}{l}\text { Increasing support } \\
\text { for a 'theme } \\
\text { park'/glamorized } \\
\text { landscape }\end{array}$ & 3 & 8 & $\sqrt{ }$ & $\sqrt{ }$ & $\sqrt{ }$ & $\mathrm{X}$ \\
\hline
\end{tabular}


Table 2: Respondent preferences for future AES delivery. $V=$ theme present within that framing of landscape stewardship; $\mathrm{X}=$ theme absent in that framing of landscape stewardship.

\begin{tabular}{|c|c|c|c|c|c|c|}
\hline Preferences & $\begin{array}{l}\text { Respondents } \\
\text { citing theme }\end{array}$ & $\begin{array}{l}\text { \% of } \\
\text { sample }\end{array}$ & Environmental & Production & Holistic & Instrumental \\
\hline $\begin{array}{l}\text { Tailor investments } \\
\text { to farm systems }\end{array}$ & 14 & 35 & $\sqrt{ }$ & $\sqrt{ }$ & $\sqrt{ }$ & $\sqrt{ }$ \\
\hline $\begin{array}{l}\text { Better } \\
\text { communication of } \\
\text { funding rules and } \\
\text { supported practices }\end{array}$ & 10 & 25 & $\sqrt{ }$ & $\mathrm{X}$ & $\sqrt{ }$ & $\sqrt{ }$ \\
\hline $\begin{array}{l}\text { Tailor investments } \\
\text { to catchments or } \\
\text { ecosystems }\end{array}$ & 8 & 20 & $\sqrt{ }$ & $\mathrm{X}$ & $\sqrt{ }$ & $\sqrt{ }$ \\
\hline $\begin{array}{l}\text { More education and } \\
\text { training courses }\end{array}$ & 7 & 18 & $\sqrt{ }$ & $\sqrt{ }$ & $\sqrt{ }$ & $\sqrt{ }$ \\
\hline $\begin{array}{l}\text { More support for } \\
\text { small holders }\end{array}$ & 6 & 15 & $\sqrt{ }$ & $\mathrm{X}$ & $\sqrt{ }$ & $\sqrt{ }$ \\
\hline $\begin{array}{l}\text { Lighter touch to } \\
\text { compliance }\end{array}$ & 6 & 15 & $\sqrt{ }$ & $\sqrt{ }$ & $\sqrt{ }$ & $\mathrm{X}$ \\
\hline $\begin{array}{llr}\text { Direct } & \text { farm } \\
\text { payment } & \text { to } & \text { the } \\
\text { manager } & & \end{array}$ & 5 & 13 & $\sqrt{ }$ & $\sqrt{ }$ & $\sqrt{ }$ & $\mathrm{X}$ \\
\hline $\begin{array}{l}\text { Higher subsidies to } \\
\text { support a range of } \\
\text { cultural values (the } \\
\text { 'playground') }\end{array}$ & 5 & 13 & $\sqrt{ }$ & $\sqrt{ }$ & $\sqrt{ }$ & $\sqrt{ }$ \\
\hline $\begin{array}{l}\text { Facilitation of } \\
\text { commoner rights }\end{array}$ & 4 & 10 & $\mathrm{X}$ & $\sqrt{ }$ & $\sqrt{ }$ & $\sqrt{ }$ \\
\hline $\begin{array}{l}\text { More support for } \\
\text { local infrastructure }\end{array}$ & 4 & 10 & $\sqrt{ }$ & $\mathrm{X}$ & $\sqrt{ }$ & $\sqrt{ }$ \\
\hline $\begin{array}{l}\text { Cease subsidies - } \\
\text { expose land } \\
\text { managers to the free } \\
\text { market }\end{array}$ & 4 & 10 & $\mathrm{X}$ & $\sqrt{ }$ & $\sqrt{ }$ & $\sqrt{ }$ \\
\hline $\begin{array}{l}\text { Promote agriculture } \\
\text { as a viable career } \\
\text { path }\end{array}$ & 3 & 8 & $\mathrm{X}$ & $\sqrt{ }$ & $\sqrt{ }$ & $\sqrt{ }$ \\
\hline $\begin{array}{lr}\text { Incentives } & \text { to } \\
\text { encourage } & \text { young } \\
\text { people into farming }\end{array}$ & 3 & 8 & $\sqrt{ }$ & $\sqrt{ }$ & $\mathrm{X}$ & $\mathrm{X}$ \\
\hline $\begin{array}{l}\text { Support for heritage } \\
\text { buildings, } \\
\text { archaeological sites } \\
\text { and } \\
\text { tourism/recreation }\end{array}$ & 3 & 8 & $\mathrm{X}$ & $\mathrm{X}$ & $\sqrt{ }$ & $\sqrt{ }$ \\
\hline
\end{tabular}




\begin{tabular}{|l|l|l|l|l|l|l|}
\hline areas & & & & & & \\
\hline $\begin{array}{l}\text { Simplify application } \\
\text { process }\end{array}$ & 2 & 5 & $\sqrt{ }$ & $X$ & $X$ & $\sqrt{ }$ \\
\hline
\end{tabular}

